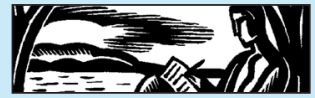

\title{
Inside the Wardrobe: Fashioning a Fashionable Life
}

\author{
Felice McDowell \\ Central Saint Martins and the London College of Fashion, \\ University of the Arts
}

\section{ABSTRACT}

This article looks to the manifestation of the personal wardrobe in digital fashion media. It focuses upon the example of British Vogue's YouTube series 'Inside the Wardrobe' and episodes that feature, firstly Vogue Fashion Editor Sarah Harris and Vogue Contributing Editor and Freelance Stylist Bay Garnett, and, secondly, acclaimed fashion blogger Susie Lau aka Susie Bubble of StyleBubble.com. In doing so it addresses ways in which fashion is an 'autobiographical act' and explores how such acts participate in the production and consumption of life narratives, and in particular the narrative of a 'fashionable life'. The article argues that fashion, in this sense, is a narrative tool employed in the fashioning of oneself and that this is strategically utilised, both consciously and subconsciously, in the field of fashion. Thus, when employed as strategic narrative tools the autobiographical acts that can fashion a self constitute the particular autobiographical form, or autobiography, that is the 'fashionable life'. In doing so this article demonstrates the contribution that the study of fashion makes to a wider understanding and knowledge of self-identity, life narrative, autobiographical acts and autobiography in digital mediums and media.

Keywords: Digital fashion media; wardrobe; autobiographical acts; cultural intermediary; fashion autobiography

\section{INTRODUCTION}

In life writing studies the emergence of digital media raises new and provocative questions, avenues of investigation and ideas about what "life" may be, in terms of its production, performance and productiveness 
within contemporary culture and society (McNeill and Zuern 2015). Much work to date has focused on various social networking platforms, such as Facebook, Twitter, Instagram, and Pinterest. These, as Madeleine Sorapure points out, 'provide a range of venues, genres, mediums, and communities in which to perform acts of self-representation', and therefore the 'often personal diaristic, self-expressive' elements and functions of Web 2.0 are forms of “everyday autobiography”' (267-268).

The commercialization of the internet in the early 1990s and its subsequent Web 2.0 format (Marwick) has also irrevocably altered the field of fashion, particularly in relation to fashion media and the blogosphere, which have witnessed a proliferation of fashion and lifestyle blogs (Mora and Rocamora). Their focus on fashion, lifestyle and self-identity has spread across social media platforms such as Twitter, Instagram, WhatsApp and Snapchat. The personal wardrobe has taken centre stage in a majority of these blogs, which "can be classified as "personal fashion blogs" or "personal style blogs"" (Titton 214).

This article takes up this recent focus on the personal wardrobe in digital media, and in particular that of the 'fashionable' and 'stylish' wardrobe as manifested by professionals from the field of fashion. It focuses on the example of British Vogue's YouTube series 'Inside the Wardrobe' (hereafter referred to as ITW $)^{1}$ and examines online videos that feature, firstly, Vogue fashion editor Sarah Harris and Vogue contributing editor and freelance stylist Bay Garnett, (British Vogue 2014) and, secondly, acclaimed fashion blogger Susie Lau, a.k.a. Susie Bubble of StyleBubble.com (British Vogue 2016). At the time of research the Vogue YouTube channel hosts 12 videos within the series, starting in 2014. They feature a range of female fashion professionals and elites such as Vogue editors, fashion models, creative directors and fashion bloggers (British Vogue 2017). These videos are highly mediated as part of the production and consumption of a high-end glossy fashion magazine and they form part of the wider conglomerate that is the global publishing giant Condé Nast. Forms of advertising that encourage the consumption of fashion within a capitalist societal framework, these videos also present fashion as a form of 'autobiographical act' (Smith and Watson 2010), and propagate the ideal of a 'fashionable life'.

Drawing upon discussions and debates that have emerged from the study of the wardrobe, fashion media, digital culture and auto/biography, I examine fashion in terms of autobiographical acts that are employed as a 'narrative tool' in the 'fashioning of life' into an autobiographical form, specifically that of the 'fashionable life' (McDowell 2017, 415; McDowell 2015). Fashion as process, practice and performance of self and identity constitutes numerous autobiographical acts in the ongoing fashioning of oneself 
(Armstrong and McDowell). Strategically utilised as a narrative tool, these autobiographical acts produce life narratives which in turn participate in the production of exchangeable forms of 'capital' operating in this field (Bourdieu 1993; Entwistle and Rocamora; Rocamora 2002). Furthermore, fashion, in the auto/biographical sense, works to define 'fashionable life' as a narrative of value that reinforces the dynamics, values, beliefs and economy of fashion for its producers, mediators and consumers.

Drawing upon Arnaud Schmitt's discussion of the nuances between what are understood to be everyday autobiographical practices or autobiographical acts and then autobiographical form and autobiographies, particularly in the realms of digital media, the present article points to how the personal wardrobe in digital space and its mediation by fashion media such as the ITW YouTube series is a particular 'autobiographical object' (Schmitt 477). Whilst fashion and the fashioning of oneself occurs in daily and everyday life, and these can be seen as a series of 'autobiographical acts', employing Schmitt's framework I point to how narratives of a 'fashionable life', mediated on digital platforms such as British Vogue's ITW series, are an autobiographical form and have been 'authored, systematised, and [...] is perceived as such' (Schmitt 2018: 483). In doing so this article proposes that fashion as both a concept and a cultural field participates in the production of the particular autobiographical form that is the 'fashionable life'.

\section{WARDROBES AND FASHION AUTOBIOGRAPHIES}

What exactly, is a 'wardrobe' and why is it relevant to discussions of both fashion and auto/biography? Jo Turney defines the wardrobe as:

\footnotetext{
both physical and imagined. In its most basic form, it is a box, a cupboard in which we store our clothes. But 'wardrobe' is also a term that we use to discuss the clothes we wear, i.e. 'I will add that to my wardrobe', as well as proposing an ideal, with terms such as 'capsule wardrobe' [...] the wardrobe is the praxis at which the ordinary self can transform through sartorial exercise $[\ldots]$.
}

The study of the wardrobe has often taken an interdisciplinary approach that emphasises what occurs between the material 'life' of clothing and the auto/biographical 'life' of its wearer. In this way the wardrobe can provide a particular and poignant space in which clothing materializes both biography and memory (Woodward). The processual practices that take place in the spatial organisation of these very objects—both clothing 
and wardrobe-can also work to co-construct a coherent subjectivity and identity (Cwerner; see also Skjold 2016; Woodward). Therefore the ways that people interact with their clothes in the spatial frame of their wardrobes are, arguably, 'autobiographical acts' (Smith and Watson 2010), productive in the formation of life narratives. ${ }^{2}$

Erving Goffman's concept of 'Identity Kits', which the individual needs 'for the management of his personal front' (Goffman [1961] 1995, 119; Cwerner) is relevant to the discussion of wardrobes, clothes and other stored items of adornment. ${ }^{3}$ The identity kit is usually kept within what Goffman calls a 'secure place' or private space, such as the bedroom. This 'identity kit' and its place form part of what Goffman identifies as regions of behaviour. It is a 'back region' where one prepares for one's social performance of self, a performance that takes place across 'front regions' outside of this space (Goffman [1959] 1969, 109-140). For most people the wardrobe is a space of storage and privacy, a 'kind of clothing library', which, as Saulo B. Cwerner suggests, 'provides the elements for numerous permutations away from the expecting eyes of the public' (Cwerner 89; Cwerner and Metcalfe). Yet our understanding of what Else Skjold has called a 'biographical wardrobe' (Skjold 2016, 136) changes when these elements take place as part of a front region performance, specifically in the public realm of mass media.

Fashion media has long been a product of modern consumer culture and it plays an intrinsic part in the negotiation of self and identity through practices of dress and adornment. Representations of the wardrobe can be traced throughout a print history of fashion, in articles and photospreads that celebrate the wardrobes of aspirational figures such as film stars, aristocrats and fashion professionals, and in myriad forms of advice literature directed at readers (Turney). Recent scholarship on personal fashion blogs has pointed to the role of the autobiographical in digital fashion media. For instance, in her examination of digital self-portraiture Agnès Rocamora argues that the self which bloggers present on their sites is 'not a visual self only but one whose external rendering is intertwined with autobiographical details' (Rocamora 2011, 410; see also Titton). This 'digital self' not only expresses the 'sartorial style of its author' but also regularly refers to information about the author's life, therefore 'Personal stories are narrated supporting the practice of fashion as a technique of the self' (Rocamora 2011, 412). Likewise, Jeff Horsely (2014) claims that the personal wardrobe as worn and performed by bloggers online can be described as 'Fashion Autobiography'. For Horsley, blogs that offer 'unmediated fashion autobiography' are sites that 'act as personal style diaries of the author's fashion choices'. One example would be UK-based Poppy Dinsey's site WhatIWore2oday (idem: 185). 
The wardrobe, then, encompasses clothes styled, presented and worn on the body of their wearer, and it features as a focal point in a number of personal blogs. Elisa Goodkin's website Stylelikeu 'places subjects in their own homes, recording their wardrobe space', thereby inviting 'the individual's autobiographic narrative reflected through clothing, gesture and location' (Horsley 185). The now defunct blog 'ShowMeYourWardrobe' of photographer and stylist Jackie Dixon 'featured snaps of people', often fashionable professionals whom Dixon 'had persuaded into letting her enter their homes and photograph them in their favourite outfits' (SHOWstudio n.d: n.p; Rocamora 2012, 103). In these instances a certain kind of fashionable wardrobe is the focal point: a wardrobe selected for its stylish owner and contents. ${ }^{4}$ However, representations of the fashionable wardrobe in both analogue and digital fashion media are neither simplistic reflections of a life lived through the consumption of clothes nor are they simply another spectacle of fashion itself. Rather, the recording and rendering of the personal wardrobe in these instances is strategically employed as a narrative tool by which autobiographical acts of fashion become a type of fashion autobiography that can bestow players in the field of fashion with certain amounts of symbolic value and relative forms of capital.

\section{FASHIONABLE LIFE NARRATIVES AND THE CULTURAL PRODUCTION OF FASHION}

The mediation of the fashionable wardrobe online is then, a mediation of a fashionable life. ${ }^{5}$ It is a type of life narrative that bestows upon its narrator certain kinds of symbolic gain, or 'capital', in what Pierre Bourdieu identifies as a 'field of cultural production' (Bourdieu 1993), which in this instance is the 'field of fashion' (Entwistle and Rocamora 2006; Rocamora 2002). For Bourdieu, a field is a semi-autonomous site in which culture is materially and symbolically produced. It is a dynamic space that continually changes-according to the struggles of various networks and/or structural relations that occur 'between social positions' of 'social agents' - these can be 'isolated individuals, groups or institutions' (Bourdieu 1993, 29). At the same time such social networks and structural relations work to maintain the field.

Another key aspect to the theory of 'cultural production' is that different kinds of 'capital' are in continuous operation within a field. These are economic, cultural, social and symbolic capital. Different social agents-institutions, groups and individuals-are all endowed with different forms of capital particular to their field. Symbolic capital refers to 
the accumulation of "legitimate capital called "prestige" or "authority" (idem: 75), cultural capital concerns 'a certain type of cultural accumulation and a certain image of cultural accomplishment' or cultural knowledge (Bourdieu [1984] 2010, 17), whilst social capital is about one's social and professional networks. Importantly, these different types of capital affect one another. One may be low in economic capital but high in cultural capital, or symbolic, cultural and social capital may lead to 'economic success' (Bourdieu 1993, 75).

As has been recognised by a number of academics, the field of fashion produces its own specific discourse that converges with the relative struggles of its agents and their shared meanings and values (Entwistle and Rocamora 2006; Rocomora 2002; Rocamora 2015; Lynge-Jorlén 2012). It has been argued that this field also produces and circulates its own forms of 'fashion capital' (Rocamora 2002, 343). According to Joanne Entwistle and Agnès Rocamora, fashion capital is 'like all fieldrelated capitals, it is made up of economic, and cultural capital [...] and social and symbolic capital' (Entwistle and Rocamora 2006, 740). The fashion press plays an integral part in how the field of fashion is both maintained and changed. Its institutions and social agents include magazines, newspapers, journalists, photographers, stylists, makeup artists and now also a range of bloggers (Rocamora 2015, 244) and other social media "influencers" (Harris). They are all 'involved in the definition of its norms and values', which includes 'the definition of what constitutes good, tasteful, valuable or innovative fashion' (Rocamora 2015, 244). Therefore it is in this way the ITW series and other digital sites which present the fashionable wardrobe produce fashionable life narratives that participate in the cultural production of fashion. The 'fashionable life' as such is not simply a reflection of a life lived in fashion but demonstrates how autobiography is also a form of value that is to be worked for, gained, bestowed and circulated within fields of cultural production. The autobiographical and fashionable life autobiography is in this sense also 'capital'.

\section{THE FASHIONABLE LIVES AND CLOTHES OF CULTURAL INTERMEDIARIES IN THE FIELD OF FASHION}

The ITW episode featuring Vogue fashion editors Sarah Harris and Bay Garnett was published online in June 2014; Susie Lau's video, in which Bay Garnett interviewed her, was published in September 2016 as a themed 'London Fashion Week Essentials' special edition (British Vogue 2014; 2016). Whilst the personal clothes collections, wardrobe space and 
professional profiles of these women are diverse, all three can be considered as 'cultural intermediaries' working in the fields of fashion and fashion media, each involved in defining their 'norms and values' (Rocamora 2015, 244). In accordance with Bourdieu's theory of cultural production, these figures and others who feature in Vogue's ITW YouTube series are social agents from within or closely associated with fashion and fashion media. As cultural intermediaries, these women occupy professional roles that are positioned between production and consumption (Bourdieu [1984] 2010). In doing so they often perform activities 'involving presentation and representation' (idem: 201). Intermediaries are 'defined by their work as taste makers' (Smith Maguire 20); however, they 'cannot enforce desires or purchases; rather, they create the conditions for consumers to identify their tastes in goods' (idem). In ITW the personal consumption of fashion is told through the space and contents of the personal wardrobe, which frames idiosyncratic narratives of a 'fashionable life'. What could otherwise be deemed superficial tales of fashion consumption instead present fashion as not only a 'personal investment' in one's work (idem: 22), but also as a series of autobiographical acts, which occur between a personal and professional self.

As cultural intermediaries Harris, Garnett and Lau each occupy different positions with the field of fashion media. In their association with Vogue and other networks spanning more 'traditional' forms of print media and sites of 'high' fashion, Harris and Garnett can be placed in more established institutions of this field. Lau, on the other hand, has emerged as an 'independent' style blogger and is therefore a relative 'outsider' (Pham). Minh-Ha T. Pham has argued that Lau's outsider status is compounded by both her individual sartorial style and, in a field 'which continues to privilege white Euro-American bodies and standards of beauty', by her racial difference from them (idem: 256). Nonetheless, 'veteran' fashion bloggers like Lau, Olivia Palermo and Leandra Medine of Manrepeller.com (also featured in the ITW series) are 'increasingly becoming consecrated' by the field of fashion media (Rocamora 2015, 245). As Rocamora points out, the symbolic capital of bloggers such as Lau has become 'arguably as valuable as that of celebrated fashion journalists such as Cathy Horyn' (idem). The inclusion in ITW of bloggers like Lau shows how relatively successful they have become. They attract attention and praise in traditional print media as well on ITW's digital platform.

In ITW, Harris, Garnett and Lau's narratives of fashionable life are told through consumer practices of the purchasing, owning, wearing and keeping of garments in the space of their wardrobes. In her ethnographical study of women, clothes and their wardrobes, Sophie Woodward 
employs Anthony Giddens' concept of 'self-identity', which is defined as 'the self as reflexively understood by the person in terms of her or his biography' (Giddens cited in Woodward 51). For Woodward, activities such as 'the wardrobe sort out' are an 'occasion on which women can also work through their biographies [...] the act of sorting out former selves through clothing is also part of [...the] process of engaging with selfidentity' (idem). In this way the wardrobe forms part of a self-reflexive biographical project, albeit one that challenges aspects of Giddens: the past is not necessarily 'terminated', as Giddens argues, but can be reactivated and 'made present through clothing' (Woodward 52, 56). In the selection and detailing of particular items from within their own personal wardrobes, Harris, Garnett and Bubble 'sort out' their wardrobes for a digital platform and an online audience, engaging in a 'self-reflexive biographical project'. However, this project also concerns the 'harmony between personal tastes and professional function and position' (Smith Maguire 22); personal investments are made by the cultural intermediary in both their sense of self-identity and then that of the capitalist market.

In detailing particular objects from their personal wardrobes, Harris, Garnett and Lau-demonstrate how material culture can be employed as a narrative tool. As Mary Douglas and Baron Isherwood point out, all 'material possessions carry social meanings' and are used as 'communicators' which 'also make and maintain social relationships' (38-39). With regard to the number of commodities originating from the realms of luxury designer-label fashion highlighted in the ITW series, these can be understood as status symbols: their 'characteristics also mark rank' in their ownership (idem: 85). Harris picks out some of her favourite shoes by labels Louis Vuitton, Gianvito Rossi and Manolo Blahnik, and a pair of 'new season Celine' trousers yet to be worn (British Vogue 2014, n.p). Garnett pulls out a Marc Jacobs Victoriana style jacket from what she calls her 'posh' cupboard. Laughingly Garnett describes how she loves this jacket: 'it's now, it's very now' although 'it's the kind of jacket that could actually lead to a divorce because it's sooo [sic] expensive' (idem). At the end of her ITW episode Lau is shown modeling potential 'Daytime' and 'Night-time' looks for London Fashion Week. The former is a Vetements floral dress, described by Lau as 'deranged granny', worn with 'grannyish glasses' by label Persol (British Vogue 2016, n.p). The latter is a pale pink tulle embroidered dress by designer Simone Roche accessorized with 'delicate gold' Miu Miu glasses (British Vogue 2016, n.p). The relative exclusiveness of these goods, in terms of access, price and knowledge of high fashion, suggests that they have been selected and presented for gain within the field of fashion, particularly if we look at the purchasing, owning and wearing of such commodities as an investment in one's 'fashion capital' within the field. 
And yet the commodities of fashion, like all material goods, are themselves a 'nonverbal medium for the human creativity faculty' (Douglas and Isherwood 41). Selecting from their personal wardrobes, Harris, Garnett and Lau participate in a highly mediated and glossy account of themselves. But there is more at stake here than mere celebration of the self and fashion. As Anna Poletti and Julie Rak point out in the analysis of identity formation online, "We can ask what the "products" of identity are and whether they are part of late capitalist circulations of goods, and we can find out who produces and who consumes certain kinds of identities' (10; see also Smith and Watson 2014). In Harris, Garnett and Lau's ITW videos material goods are both products of and productive in the formation of personal identities and, simultaneously, professional positions within the field of fashion. In this way fashion as a narrative tool presents a 'harmony between the personal and professional' (Smith Maguire 22). The circulation of goods and 'reproduction of consumer economies' within late capitalist society in part 'rests on the personal, affective investments of its promoters' (idem: 23). And while this may be consciously or unconsciously strategic, it is also no less a 'sincere disposition' in the sense that in order to reach some level of relative success cultural intermediaries often 'inhabit' their 'occupations and embody their intended markets' (idem: 22-23).

\section{FASHIONABLE WARDROBE SPACE PERSONIFIED}

Space has been considered as part of the consumption, circulation and communication of commodities and material goods. As Douglass and Isherwood argue, 'Harnessed to the cultural process, [spatial] divisions are heavy with meaning: housing, size, the side of the street, distance from other centers, special limits, all shore up conceptual categories' (44). Additionally in histories of modernity, fashion and its interior space has been read as forming a significant part of the production of self-identity (see Fisher et al.; McDowell 2015). The ITW videos largely take place in 'private' domestic spaces such as the interviewees' apartments, houses and bedrooms. For Cwerner, the wardrobe 'is also an object of consumption itself, as [a] part of modern home furniture [...] Wardrobes not only house fashion, but they are also objects of taste and fashion in the house' (81). As with the material objects of high luxury fashion selected from ITW interviewees' personal wardrobes, the personal wardrobe space itself is a matter of meaning, value, capital and fashion.

In the ITW episode featuring Harris and Garnett, the viewer is presented with two different styles of wardrobe space. Harris' wardrobe is a 
specially-built walk-in. As she explains, 'We built the house about three years ago and the only kind of element of the house that I was really concerned with was the wardrobe' (British Vogue 2014, n.p). She 'really wanted the wardrobe to feel a bit like a jewellery box, um [sic], in the middle of the bedroom' (idem). Cupboards, drawers and shelves were designed to exacting specifications. Glamorous and custom-built, Harris' personal wardrobe appears organised and immaculate. Garnett's wardrobe appears to be the opposite. Described by Garnett as unorganised, 'in a way it's a bit like a thrift store, kind of everythings [sic] is everywhere, but it kind of makes sense to me' (British Vogue 2014 n.p). She shows the camera to two main cupboards in her bedroom which comprise her own personal wardrobe space, one of which she labels her 'posh' cupboard. In the later Susie Bubble ITW episode, Garnett greets Lau's walk-in wardrobe with the exclamation: 'O wow. I'm really envious of your walk-inwardrobe, I'd love to have a walk-in-wardrobe' (British Vogue 2016, n.p). Although modest in size and scale compared to Harris's wardrobe and the wardrobes of some of the other figures who have featured in the ITW series, it nonetheless remains comparatively impressive in terms of how Lau's recognisably colourful and 'Pop-y' personal style emanates from within what is otherwise a basic rectangular space just large enough to accommodate interviewer, interviewee and a camera. Her personal style spills out into the rest of her home in the way that numerous fashion accessories, bags, shoes and hats, appear on walls, doors and shelves, part excess storage and part décor.

The personal wardrobe space of Harris, Garnett and Lau each forms part of their own 'fashionable persona' in that the mediation of the personal wardrobe space online is 'embedded in established fashion narratives and [...] based on references to the self and self-representation' (Titton 203). In her study of fashion bloggers Monica Titton outlines her concept of the 'fashionable persona' as 'a dynamic process of selfcreation' which constitutes 'a gradual blurring of the distinction between bloggers' factual, lived, and experienced biographies and their enactment and appropriation of fashion narratives' (idem 209). For Titton, a 'fashionable persona' 'unfolds in a narrative practice-in the form of the production of fashion texts based on their personal experience-and in bodily practices - in the form of enactment and incorporation of a certain "grammar" of corporeal postures and behaviour' (idem). Thus a 'distinct character, or persona is formed' (idem, emphasis in original). The material contents and space of these fashionable wardrobes indeed contribute to the character, and professional personae, of Harris, Garnett and Lau. As British Vogue fashion editor, Harris has a highly ordered and uniform wardrobe and collection of stylish and expensive fashion 'staples'. 
Garnett's wardrobe, with an eclectic mix of luxury fashion and thrift shops buys seemingly unordered and mixed together, reflects her job as a fashion stylist. ${ }^{6}$ Lau's walk-in-wardrobe has its own online media presence and celebrity, working in conjunction with Lau's role as a 'personal fashion blogger' (for example see Rose; Lau; Forster).

Digital media has 'diversified the ways in which people present themselves to others' and has reshaped social practices of self-presentation and representation (Titton 209-210). Titton argues that fashion bloggers 'constantly actualize and re-inform their presentation of self and engage in the construction of a particular form of mediatized self-narration' which is their 'fashionable persona' (idem: 210). The ITW YouTube series points to how within the field of fashion a range of social agents and cultural intermediaries are utilising digital media and how this contributes to the construction and circulation of their 'fashionable persona'. Whilst the 'sartorial biography' (Cwerner 81) of the wardrobe provides the self with sets of narrative tools concerning our relationship with dress, body and material space, in these instances of digital media the fashionable wardrobe space is space personified.

This form of self-promotion promotes fashion and vice-versa. It is both a product of and producer of life narratives, in particular that of the fashionable life. Here fashion is performed as a series of autobiographical acts. However, these acts traverse the autobiographical and autobiography in that the personal and professional narratives of a fashionable life are, in conjunction with British Vogue, authored by these women, they are publicised and 'fixed in a medium that can outlast its mundanity' (Schmitt 479). In this medium, that is in this instance the YouTube video, the self of the cultural intermediary is 'embodied beyond its own body, beyond its own social circle [...] perceivable by someone else who doesn't belong to this circle' (idem). Viewed and consumed by an online audience, the personal wardrobes and fashionable lives of Harris, Garnett and Lau are autobiographical forms made into fashion autobiography that circulates across networks of culture and consumption.

\section{AUDIENCES OF THE FASHIONABLE WARDROBE AND FASHIONABLE LIVES}

The ways in which a range of cultural intermediaries from the field of fashion, each with varying levels of field-related capital, perform their fashionable wardrobes, and therefore articulate a fashionable life autobiography, throughout the ITW series is, as previously noted, not alien to a history of fashion media. In her discussion of fashion print media and 
the representation of intermediaries within fashion features and editorial photo-spreads, Sylvie Richoux-Bérard argues that 'Journalists, models, artistic directors and photographers become objects of imitation in their own right' (176). This type of representation continues to take place across fashion media. But the ways in which the personal wardrobe is enacted, embodied and performed online invites one to question how the practices of fashion editors, journalists, stylists, and other figures associated with hierarchies of fashion media have altered for and with digital media. Arguably it would appear that within the participatory nature of digital culture (Jenkins et al.), values more readily associated with the work and persona of the fashion blogger, such as a sense of 'individuality', 'intimacy', and 'authenticity' (Rocamora 2018), are increasingly the values that contribute to the consecration and legitimation of numerous other intermediaries within a networked field of fashion.

In his classic discussion of intimacy and space, Gaston Bachelard describes how wardrobes are 'veritable organs of the secret psychological life' and how without these objects 'our intimate life would lack a model of intimacy' (78). As 'hybrid objects, subject objects' they are 'Like us, through us and for us [and therefore] have a quality of intimacy' (idem). Yet it would appear for Bachelard in order for a wardrobe's inner space to become an 'intimate space', it must be a space 'that is not open to just anybody' (idem, emphasis in original).

In the ITW YouTube series and other examples of digital fashion media, the personal wardrobe and personal wardrobe space form part of a public presentation of self in digital spaces that, theoretically, are open to anybody. The experience of intimacy with this object and its contents becomes an experience of intimacy between the self and an online audience (Findlay). In the case of ITW the symbiotic relationship between 'personal tastes and professional function and position' (Smith Maguire 22) is part of that intimacy.

In this sense the ways in which participants $d o$ fashion in the ITW YouTube series concerns both viewer imitation but also viewer participation. If one considers the number of audience views, likes/dislikes, and hyperlinks a YouTube video attracts, alongside the types of comments and replies embedded below it on the host webpage, they all accumulate to bestow, or not, certain kinds of validation on both the product and the producers involved. Harris and Garnett's 2014 episode had a recorded 515,169 views, whilst Lau's 2016 episode recorded 200,774 views (British Vogue 2017). The comments made by some viewers show that visits to these videos remain ongoing and span from the time of publication to a more recent period of time, suggesting that there is a continual and active digital audience. 
In comments made by viewers, the word 'style' rather than 'fashion' is more often employed throughout largely celebratory endorsements of featured interviewees and their associated personal wardrobes. Indeed 'style' rather than 'fashion' or being 'fashionable' appears to form a core value for these viewers as they freely associate it with ideals such as individualism, identity, 'truth' and 'authenticity' throughout their posted comments. For instance, in response to the Harris and Garnett episode 'Reit Tait 2' writes:

These women are so inspiring. Both equally as fantastic. The thing about style that they both prove is you can't buy it. You can wear all the latest designer pieces but if you don't have style you just look like a dick lol.

(British Vogue 2014, n.p).

Another viewer, 'lapetitenellie', comments: "They're both so fabulous in their own way. Just goes to show STYLE is all about being comfortable with yourself" (idem). Posts on Lau's ITW episode suggest an even greater investment in the idea of her personal 'style'. For example, 'Emily Furr' writes that Lau is:

just so honest and unapologetic, I really admire her as a female icon for our generation! I love her unique style and her passion for individuality, she's so set on expressing herself and not being a sheep in the pack. She makes me smile.

(British Vogue 2016, n.p)

Here, 'style' also acts as a byword for individual 'integrity' within the field of fashion. For instance 'Nirrini' comments that:

She has a whole different style compared to fashion bloggers today who wear everything trendy and follow each other etc. I love that fact that she is honest about her style and her no-nonsense approach is very charming. Also her hair is that of perfection.

(British Vogue 2016, n.p)

According to Susan Kaiser, 'style' can be understood as 'a process or act of managing appearance in everyday life' (80). In her conceptual framework, referred to as 'minding appearances', style also concerns 'truth' and 'subjectivity', and draws attention to 'the continual interplay between an individual and his/her various identities and communities in such a way that combines style, truth and subjectivity' (idem). Therefore 'appearance style becomes a working model or a tentative truth claim about identity (i.e. who I am, who I am not, who I may be becoming)' 
(idem). In this sense 'style', as opposed to fashion, contributes not just to the values and beliefs that circulate within the wider field of fashion but also to the value of an individual identity and the individual life narrative. In digital fashion media, the personal wardrobe space is part of 'minding appearances' in that it is both projected and viewed as a 'truth claim' concerning one's personal 'style'; it is the material space of fashion in which 'processes in everyday life, individual and collective actions become intertwined' (idem). As one viewer, 'Clawdia \& the Tartarus', comments on the Harris and Garnett ITW episode: 'Fascinating how you see the way they are in life manifested and symbolized through their clothing' (British Vogue 2014, n.p).

The personal style of cultural intermediaries from within the field of fashion has symbolic value that forms part of their 'fashion capital' which is continually assessed, evaluated and legitimated, or not, by other players, social agents and institutions within that field. Due to the nature of the personal investment required, 'minding appearance', in terms of 'style', 'truth' and 'subjectivity', forms another part of one's potential and actualized capital, whether symbolic, cultural or economic. In the participatory space of digital media, the members of a relatively open audience also proffer other forms of value, which nonetheless contribute to the aforementioned capital/s of said fashion intermediary. According to Kaiser the 'truth claim' of 'minding appearance' is continually being assessed. Moreover, 'Individuals compare ongoing imaginations and evaluations of various communities' to their appearance styles. They also come to know themselves as they think with appearance' (Kaiser 90).

In the ITW episodes the personal wardrobe and personal wardrobe space contribute to the evaluation of these intermediaries' personal style as well as acting as an assessment of their individual 'truth' and 'subjectivity'. Yet, as Kaiser points out, this evaluation and assessment takes place individually and in a community; our understanding of style, truth and subjectivity is in a continual dialogue. In a number of comments posted on the ITW YouTube video series, viewers openly reflect upon their own 'style' in comparison to those persons, clothes and wardrobe spaces featured. In response to the Harris and Garnett episode, 'Because Amy Says' writes: 'Love, love, love this video edit. Very fun and interesting. Sarah and I are two peas in a pod style wise, so very intrigued to see the home base of her style' (British Vogue 2014, n.p).

Histories of how personal style is utilized as a narrative tool in the rendering of a fashionable life are evident within a variety of print cultures concerning fashion (McDowell 2017). In this way the simple, or even complex autobiographical acts associated with fashion, style and dress, become an autobiography, as 'to be regarded as an autobiography, 
the putative autobiographer must become an author by turning her selfnarrative into a public statement and, above all, must succeed in drawing the public's interest' (Schmitt 482). Digital media have, however, altered the terms on which fashionable life narratives are produced and consumed as fashion autobiographies, as they are performed, evaluated and assessed in continual and growing dialogue between individuals and various communities 'in' and 'outside' the field of fashion, both off and online.

\section{CONCLUSION}

The modern study of auto/biography continues to expand its interest in questioning the relationship between the 'self' as it is lived and the 'self' whose lived experiences are recorded in various media, both print and digital. Whether written, recorded or performed, narrative or nonnarrative, by either that same 'self' or by another, what remains key to exploring these elements in life writing scholarship is asking how the telling of one's life tells one (or another) of one's self (McNeill and Zuern vii). In paying close attention to the mediation of the fashionable wardrobe online this article has pointed to the ways in which autobiographical acts associated with the personal wardrobe and personal wardrobe space can form a fashion autobiography. This type of autobiography, the 'fashionable life' as I have termed it here, participates in the cultural production of fashion and the accumulation and circulation of capital relative and relevant to the field of fashion media.

Furthermore the narrative of a 'fashionable life', as proffered by 'ITW' and other instances of digital fashion media, suggests to its viewers and consumers ways in which autobiographical acts and practices of the self concerning fashion, style and identity may be utilised in the fashioning of oneself. This can prove to be both advantageous and disadvantageous if one considers that in the narrative of a 'fashionable life', in order to achieve 'style', and therefore 'truth' and 'subjectivity' (Kaiser) in the eyes of oneself and others, whether one is located 'in' or 'outside' the immediate of field of fashion, one is compelled to consume fashion and it is in the consumption of fashion as such which one validates one's own fashioned life, whether fashionable or not.

\section{WORKS CITED}

Armstrong, Leah and Felice McDowell. Fashioning Professionals: Identity and Representation at Work in the Creative Industries. London: Bloomsbury, 2018. 
Bachelard, Gaston. The Poetics of Space. Trans. Jolas, Maria. Boston: Beacon Press, [1958] 1994.

Bourdieu, Pierre. Distinction. Trans. Nice, Richard. London: Routledge, [1984] 2010.

Bourdieu, Pierre. The Field of Cultural Production: Essays on Art and Literature. Trans. Johnson, Richard. Cambridge: Polity Press, 1993.

British Vogue. "Inside the Wardrobe." https://www.youtube.com/user/vogue. 22 May 2017. Web.

British Vogue. "Vogue Fashion Editors-Sarah Harris \& Bay Garnett: Inside the Wardrobe: British Vogue." 2014. https://www.youtube.com/watch?v=b9XYZYEiWYY\&list=PLHlf mUA9UkXaVpIfWwD7y_EjnsL9P6IVY\&index=7. 22 May 2017. Web.

British Vogue. "Susie Bubble: London Fashion Week Essentials: Inside the Wardrobe: British Vogue." 2016. https://www.youtube.com/watch? $\mathrm{v}=\mathrm{O}$ wiNRmtx88\&index $=10$ \&list $=\mathrm{PL}$ HlfmUA9UkXaVpIfWwD7y_EjnsL9P6IVY. 22 May 2017. Web.

Cwerner, Saulo B. "Clothes at Rest: Elements for a Sociology of the Wardrobe." Fashion Theory: The Journal of Dress, Body and Culture 5.1 (2001): 79-92.

Cwerner, Saulo B. and Alan Metcalfe. "Storage and Clutter: Discourses and Practices of Order in the Domestic World." Journal of Design History 16.3 (2003): 229-239.

Douglas, Mary and Baron Isherwood. The World of Goods: Towards an Anthropology of Consumption. London: Routlege, 1996.

Entwistle, Joanne. The Fashioned Body: Fashion, Dress and Modern Social Theory. Cambridge: Polity Press, 2000.

Entwistle, Joanne and Agnès Rocamora. "The Field of Fashion Materialized: A Study of London Fashion Week." Sociology 40.4 (2006): 743-751.

Findlay, Rosie. Personal Style Blogs: Appearances that Fascinate. Bristol: Intellect, 2017.

Fisher, Fiona, Trevor Keeble, Patricia Lara-Betancourt and Martin Brenda. Performance, Fashion and the Modern Interior: From the Victorians to Today. London: Bloomsbury, 2011.

Forster, Katie. "Life in the Bubble: My Small and Colourful Home". The Guardian 2016. https://www.theguardian.com/fashion/2016/feb/21/my-small-and-colourful-homesusie-bubble-lau. 18 May 2017. Web.

Goffman, Erving. The Presentation of Self in Everyday Life. London: Penguin, [1959] 1969.

Goffman, Erving. "Identity Kits." Eds. Roach-Higgins, Mary Ellen, Joanne B. Eicher and Kim P. Johnson. Dress and Identity. New York: Fairchild Publications, [1961] 1995. 119-120.

Harris, Sarah. "What Is An Influencer?" British Vogue 2017. http://www.vogue.co.uk/article/what-is-an-influencer. 19 November 2017. Web.

Horsley, Jeff. "Autobiography as a Proposed Approach to a Fashion Exhibition." Eds. Riegels Melchior, Marie and Birgitta Svensson. Fashion and Museums: Theory and Practice. London: Bloomsbury, 2014. 180-196.

Jansson, André. "Mediatization and Social Space: Reconstructing Mediatization for the Transmedia Ages." Communication Theory 23 (2013): 279-296.

Jenkins, Henry, Mizuko Ito and Danah Boyd. Participatory Culture in a Networked Era. Cambridge and MA: Polity Press, 2016.

Kaiser, Susan. "Minding Appearances: Style, Truth, and Subjectivity." Eds. Entwistle, Joanne and Elizabeth Wilson. Body Dressing. London and New York: Berg, 2001. 79-102.

Lau, Susie. "Neon Lines." Style Bubble 2014. http://stylebubble.co.uk/style_bubble/2014/01/ neon-lines.html. 25 May 2017.

Lifter, Rachel. "Fashioning Pop: Stylists, Fashion Work and Popular Music Imagery." Eds. Armstrong, Leah and Felice McDowell. Fashioning Professionals: Identity and Representation at Work in the Creative Industries. London: Bloomsbury, 2018. 51-64.

Lynge-Jorlén, Ane. "Between Frivolity and Art: Contemporary Niche Fashion Magazines." Fashion Theory: The Journal of Dress, Body and Culture 16.1 (2012): 7-28. 
Lynge-Jorlén, Ane. "Editorial Styling: Between Creative Solutions and Economic Restrictions." Fashion Practice 8.1 (2016): 85-97.

Marwick, Alice E. Status Update: Celebrity, Publicity and Branding in the Social Media Age. NH and London: Yale UP, 2013.

McDowell, Felice. “The Influence of Anthony Denney': Authorship in the Production and Consumption of British Fashion Media in the Late 1950s." Photography E $\mathcal{F}^{2}$ Culture 8.3 (2015): 253-267.

McDowell, Felice. "Sketching a silhouette: Histories of life and fashion in 'Isabella Blow: Fashion Galore!'” The International Journal of Fashion Studies 2.2 (2015): 325-330.

McDowell, Felice. "Fashioning a Life: Exploring How Fashion Literature Fashions the Self." $a / b$ : Auto/Biography Studies 32.2 (2017): 414-416.

McDowell, Felice. "Model Tote Bags: Advice on How to Perform the Fashionable Self in Postwar Fashion Modelling Literature." About Performance 16 (2018): 45-60.

McNeill, Laurie and David Zuren. "Online Lives 2.0: Introduction." Biography 38.2 (2015): v-xlvi.

McRobbie, Angela. British Fashion Design: Rag Trade or Image Industry? London and New York: Routledge, 1998.

Mora, Emauela and Agnès Rocamora. "Letter from the Editors: Analysing Fashion BlogsFurther Avenues for Research." Fashion Theory: The Journal of Dress, Body and Culture 19.2 (2015): 149-156.

Pham, Minh-Ha T. "Susie Bubble is a Sign of The Times." Feminist Media Studies 13.2 (2013): $245-267$.

Poletti, Anna and Rak, Julie. Identity Technologies: Constructing the Self Online. Wisconsin: University of Wisconsin Press, 2014.

Richoux-Bérard, Sylvie. "Do It!" Eds. Richoux-Bérard, Sylvie and Frederic Bonnet. Glossy: Modes et Papier Glacé. Marseille: Musée de la Model de Marseille, 2004. 176-177.

Rocamora, Agnès. "Fields of Fashion: Critical Insights into Bourdieu's Sociology of Culture." Journal of Consumer Culture 2.3 (2002): 341-362.

Rocamora, Agnès. "Personal Fashion Blogs: Screens and Mirrors in Digital Self-portraits." Fashion Theory: The Journal of Dress, Body and Culture 15.4 (2011): 407-424.

Rocamora, Agnès. "Hypertextuality and Remediation in the Fashion Media." Journalism Practice 6.1 (2012): 92-106.

Rocamora, Agnès. "Pierre Bourdieu: The Field of Fashion.” Eds. Rocamora, Agnès and Anneke Smelik. Thinking through Fashion: A Guide to Key Theorists. London: I.B. Tauris, 2015. 233-250.

Rocamora, Agnès. "Mediatization and Digital Media in the Field of Fashion." Fashion Theory: The Journal of Dress, Body and Culture 21.5 (2017): 505-522.

Rocamora, Agnès. "The Labour of Fashion Blogging." Eds. Armstrong, Leah and McDowell, Felice. Fashioning Professionals: Identity and Representation at Work in the Creative Industries. London: Bloomsbury, 2018. 65-81.

Rose, Katherine Anne. "At home with Susie Lau-in picture." The Observer 2016. https://www.theguardian.com/fashion/gallery/2016/feb/20/at-home-with-susie-bubble-lau-in-pictures. 18 May 2017. Web.

Schmitt, Arnaud. "From Autobiographical Act to Autobiography." Life Writing 15.4 (2018): 469-486.

SHOWstudio. "Jackie Dixon-Photographer.” http://showstudio.com/contributor/jackie_ dixon. 20 May 2017. Web.

Skjold, Else. "Biographical Wardrobes-A Temporal View on Dress Practice." Fashion Practice: The Journal of Design, Creative Process E the Fashion Industry 8.1 (2016): 135-148.

Skjold, Else. "Adorned in Dreams: Reversing the Gaze: From the Look of Fashion to the Lens of the Wardrobe." Clothing Cultures 4.1 (2017): 13-28. 
Smith, Sidonie and Julia Watson. Reading Autobiography: A Guide for Interpreting Life Narratives. $2^{\text {nd }}$ ed. Minneapolis and London: University of Minnesota Press, 2010.

Smith, Sidonie and Julia Watson. "Virtually Me: A Toolbox about Online Self-Presentation." Eds. Poletti, Anna and Julie Rak. Identity Technologies: Constructing the Self Online. Wisconsin: University of Wisconsin Press, 2014. 70-95.

Smith Maguire, Jennifer. "Bourdieu on Cultural Intermediaries." Eds. Smith Maguire, Jennifer and Julian Matthews. The Cultural Intermediaries Reader. LA, California: Sage, 2014. $15-24$.

Sorapure, Madeleine. "Autobiography Scholarship 2.0? Understanding New Forms of Online Life Writing." Biography 38.2 (2015): 267-272.

Titton, Monica. "Fashionable Personae: Self-identity and Enactments of Fashion Narratives in Fashion Blogs." Fashion Theory: The Journal of Dress, Body and Culture 19.2 (2015): 201-220.

Turney, Jo. "Editorial." Clothing Cultures 4.1 (2017): 5-11.

Woodward, Sophie. Why Women Wear What They Wear. Oxford and New York: Berg, 2007.

\section{ABOUT THE AUTHOR}

Felice McDowell is an Associate Lecturer in Fashion History and Theory at Central Saint Martins and in Cultural and Historical Studies at the London College of Fashion, University of the Arts London. Her current research interests are in methodologies of fashion history, archival research, critical theory, life writing, and the visual and textual representation of fashion "work". She has been published in the journals Fashion Theory, Photography $\mathcal{E}^{\circ}$ Culture, Clothing Cultures, $a / b$ : Auto/Biography Studies and About Performance. She is co-editor of Fashioning Professionals: Identity and Representation at Work in the Creative Industries (Bloomsbury, 2018). Email: f.mcdowell@fashion.arts.ac.uk.

\section{NOTES}

1 Hereafter when I refer to Vogue I refer to the British publication and its associated digital media platforms.

2 I draw upon Sidonie Smith and Julia Watson's notion of 'life narrative': for Smith and Watson, life narrative works as a 'general term for acts of self-presentation of all kinds and in diverse media that take the producer's life as their subject, whether written, performative, visual, filmic, or digital'; whilst the term 'Life writing' may be employed for 'written forms of the autobiographical', and 'life narrative' refers 'to autobiographical acts of any sort' (Smith and Watson 2010, 4).

3 I also employ Goffman's notion of 'Identity Kits' in the analysis of post-war fashion modelling advice literature and its representation of the fashion model 'tote' bag as a particular kind of transitory and temporal working wardrobe space (McDowell 2018).

4 The fashionable wardrobe continues to manifest throughout personal or 'independent' fashion blogs and also on commercial and 'institutional' fashion blogs such as the coveteur.com. A number of these sites, both independent and institutional, have published analogue books dedicated to the subject of fashionable wardrobes. Arguably this points to yet another instance of 'fashion remediation' that takes place between digital and print media (see Rocamora 2012). 
5 Many forms of fashion media participate in both the mediation and the mediatization of personal wardrobe space. Whereby mediation describes the way that media act as 'conveyors of meaning', effecting 'the transmission and circulation of messages' typically through image and text (Rocamora 2016, 507-508), 'mediatization' refers to media's "transformative power" (idem, emphasis in original; see also Jansson). In the field of fashion mediatization questions not just how fashion is communicated through media, but also processes of 'doing fashion through the media' (Rocamora 2016, 509). In the case of the personal wardrobe and personal wardrobe space, one can begin to hypothesise how identity, selfrepresentation and narrative practices participate in processes of mediatization.

6 For further discussion of the relationship between fashion and 'thrift' in the history and practice of styling and stylists see Lynge-Jorlén, McRobbie and Lifter. 